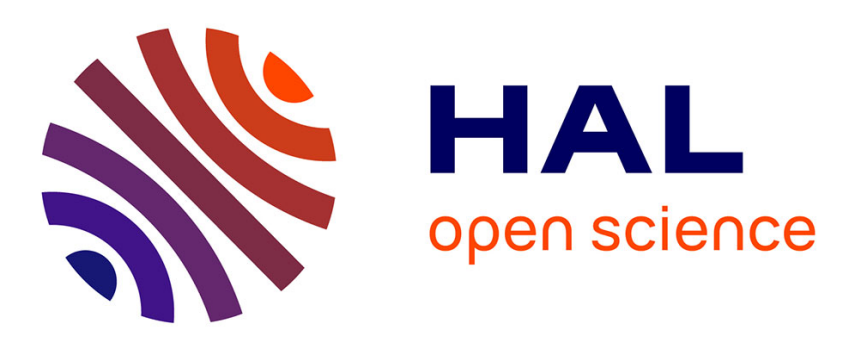

\title{
Analgesic effects of mambalgin peptide inhibitors of acid-sensing ion channels in inflammatory and neuropathic pain
}

Sylvie Diochot, Abdelkrim Alloui, Précillia Rodrigues, Mélodie Dauvois, Valérie Friend, Youssef Aissouni, Alain Eschalier, Eric Lingueglia, Anne Baron

\section{- To cite this version:}

Sylvie Diochot, Abdelkrim Alloui, Précillia Rodrigues, Mélodie Dauvois, Valérie Friend, et al.. Analgesic effects of mambalgin peptide inhibitors of acid-sensing ion channels in inflammatory and neuropathic pain. Pain, 2016, 157 (3), pp.552-559. 10.1097/j.pain.0000000000000397 . hal-02267118

\section{HAL Id: hal-02267118 \\ https://hal.science/hal-02267118}

Submitted on 20 Aug 2019

HAL is a multi-disciplinary open access archive for the deposit and dissemination of scientific research documents, whether they are published or not. The documents may come from teaching and research institutions in France or abroad, or from public or private research centers.
L'archive ouverte pluridisciplinaire HAL, est destinée au dépôt et à la diffusion de documents scientifiques de niveau recherche, publiés ou non, émanant des établissements d'enseignement et de recherche français ou étrangers, des laboratoires publics ou privés. 


\title{
Analgesic effects of mambalgin peptide inhibitors of acid-sensing ion channels in inflammatory and neuropathic pain
}

Sylvie Diochot ${ }^{1,2,3}$, Abdelkrim Alloui ${ }^{4,5}$, Précillia Rodrigues ${ }^{1,2}$, Mélodie Dauvois ${ }^{1,2}$, Valérie Friend $^{1,2,3}$, Youssef Aissouni ${ }^{4,5}$, Alain Eschalier ${ }^{4,5,6}$, Eric Lingueglia ${ }^{1,2,3 * \#}$, Anne Baron ${ }^{1,2,3^{* \#}}$

1: CNRS, Institut de Pharmacologie Moléculaire et Cellulaire, UMR 7275, 06560 Valbonne, France.

2: Université de Nice Sophia Antipolis, UMR 7275, 06560 Valbonne, France.

${ }^{3}$ : LabEx Ion Channel Science and Therapeutics, UMR 7275, 06560 Valbonne, France.

${ }^{4}$ : Clermont Université, Université d'Auvergne, NEURO-DOL, BP 10448, F-63000 ClermontFerrand, France.

5: Inserm, U1107, F-63001 Clermont-Ferrand, France.

${ }^{6}$ : CHU Clermontferrand, Service de Pharmacologie, F-63003 Clermont-Ferrand.

* E.L. and A.B. contributed equally to this work.

\# Corresponding authors.

\begin{abstract}
Mambalgins are 57-amino acid peptides isolated from snake venom that evoke naloxoneresistant analgesia after local (intraplantar) and central (intrathecal) injections through inhibition of particular subtypes of Acid-Sensing Ion Channels (ASICs). We now show that mambalgins also have an opioid-independent effect on both thermal and mechanical pain upon systemic intravenous (i.v.) administration and are effective against neuropathic pain. By combining the use of knockdown and knockout animals, we show the critical involvement of peripheral ASIC1b-containing channels, along with a contribution of ASIC1a-containing channels, in the i.v. effects of these peptides against inflammatory pain. The potent analgesic effect on neuropathic pain involves two different mechanisms depending on the route of administration, a naloxone-insensitive and ASICla-independent effect associated with i.v. injection, and an ASIC1a-dependent and partially naloxone-sensitive effect associated with i.t. injection. These data further support the role of peripheral and central ASIC1-containing channels in pain, demonstrate their participation in neuropathic pain, and highlight differences in the repertoire of channels involved in different pain conditions. They also strengthen the therapeutic potential of mambalgin peptides that are active in a broader range of experimental pain models and through i.v. systemic delivery.
\end{abstract}




\section{Introduction}

Acid-Sensing Ion Channels (ASICs) are voltage-insensitive, proton-gated cation channels activated by extracellular acidosis [23]. In rodents, four genes encode at least six different subunits, the variants ASIC1a and ASIC1b, the variants ASIC2a and ASIC2b, ASIC3 and ASIC4 $[5 ; 13 ; 25]$. Three identical or different subunits are required to form a functional channel (except for ASIC2b and ASIC4, which do not form proton-gated channels when expressed alone). ASIC1a and ASIC2 (both variants a and b) are widely expressed in neurons of the central nervous system, while almost all subunits (except ASIC4) are present in sensory neurons of the peripheral nervous system including nociceptors [6;16].

Peptide toxins derived from animal venoms that specifically target different subtypes of ASIC channels have been instrumental in the exploration of the role of these channels in pain in rodents $[1 ; 2]$. In the peripheral nervous system, local intraplantar (i.pl.) injections of APETx2, a sea anemone toxin that blocks ASIC3-containing channel [9], decrease pain produced by acid, inflammation, local incision and osteoarthritis, supporting the participation of peripheral ASIC3-containing channels in pain associated with these conditions $[7 ; 8 ; 14$; 15]. MitTx isolated from the Texas coral snake's venom evokes pain after local injection through the activation of peripheral ASIC1 channels [4]. Finally, i.pl. mambalgin peptides isolated from mamba venoms induce a potent analgesia on acute pain and inflammatory hyperalgesia through inhibition of ASIC1b-containing channels in nociceptors $[1 ; 10]$.

In the central nervous system, intrathecal (i.t.) injection of the spider psalmotoxin 1 (PcTx1), which selectively blocks ASIC1a homomeric and ASIC1a/ASIC2b heteromeric channels $[11 ; 20]$ results in potent analgesic effects against chemical, inflammatory and neuropathic pain in rodents revealing the important role of homomeric ASIC1a, and probably heteromeric ASIC1a/ASIC2b channels in central neurons in pain modulation though activation of the endogenous enkephalin pathway [17]. Mambalgins (i.t.), which are inhibitors of ASIC1-containing channels with a broader pharmacological profile than PcTx1, also show a potent analgesic effect in rodents that is opioid-independent (i.e., resistant to the opioidantagonist naloxone, contrary to the effect of PcTx1) and involves heteromeric channels made of ASIC1a and ASIC2a subunits [10].

It is essential to better understand pain in view to develop new analgesics. Mambalgins are particularly interesting in this regard because they inhibit different subtypes of ASIC channels to evoke analgesic properties after local (i.pl.) and central (i.t.) injections on acute and inflammatory pain [10]. We propose here to extend our previous work by exploring the 
analgesic activity of these peptides and their mechanism of action following systemic intravenous (i.v.) administration and in an experimental model of neuropathic pain.

\section{Methods}

\subsection{Drugs and in vivo injections}

Mambalgin-1 and Mambalgin-3 were purified as previously described [10] from Dendroaspis polylepis polylepis and Dendroaspis angusticeps venoms (Latoxan, France), respectively. Synthetic mambalgin-1 (sMamb-1) was synthetized by Synprosis/Provepep (Fuveau, France).

Experiments were performed on 7-13 week-old (20-25g) male or female wild-type C57BL/6J (Charles River), ASIC1a-knockout [24] and ASIC2-knockout mice [12]. No major basal pain phenotype has been described in these animals [21;22], most probably because of compensatory mechanisms. Animal procedures were approved by the Institutional Local Ethical Committee and the French "Ministère de la Recherche" according to the European Union regulations (Agreements C061525, NCE/2011-06 and 01550.03).

For i.v. injections, mambalgin-1 (Mamb-1 or sMamb-1, $1.7 \mu \mathrm{M})$, mambalgin-3 (Mamb-3, $1.7 \mu \mathrm{M})$ and morphine- $\mathrm{HCl}(1.5 \mathrm{mM}$; Cooper) were dissolved in $200 \mu 1$ saline $(\mathrm{NaCl} 0.9 \%)$, and injected in the caudal vein with a $30 \mathrm{G}$ needle. For i.t. injections, mambalgin-1 (Mamb-1 or sMamb-1, $34 \mu \mathrm{M}$ ), mambalgin-3 (Mamb-3, $34 \mu \mathrm{M}$ ) and morphine-HCl (3.1 mM; Cooper) were dissolved in $10 \mu$ l vehicle solution (in $\mathrm{mM}$ : $\mathrm{NaCl} 145, \mathrm{KCl} 5, \mathrm{MgCl}_{2} 2, \mathrm{CaCl}_{2}$ 2, HEPES 10, $\mathrm{pH}$ 7.4) and injected between spinal L5 and L6 segments. Bovine serum albumin (0.05\%) was added in all final dilutions to prevent toxin non-specific adsorption. When needed, naloxone (Fluka, $2 \mathrm{mg} / \mathrm{kg}$ in saline, $50 \mu \mathrm{l}$ ) was subcutaneously (s.c., dorsal injection) injected 10 minutes before $i . v$ or $i . t$ injections of peptides, morphine or vehicle, in order to inhibit opioid receptors. The same protocol was previously shown to fully inhibit the enkephalindependent analgesia induced by i.t. injection of the ASIC-inhibitory peptide PcTx1 [10; 17].

\subsection{Motor behaviour tests}

\subsubsection{Accelerated Rotarod test}


Mice were placed onto the dowel of an accelerating Rotarod treadmill (Bioseb) rotating at $4 \mathrm{rpm}$ and then accelerating at a constant rate of $5 \mathrm{rpm} / \mathrm{min}$ up to $40 \mathrm{rpm}$ [18]. The latency to fall to the floor was recorded, with a maximum cut-off latency of $300 \mathrm{sec}$. Mice were trained during two days before being tested, and each trial was done in duplicate. The time-course of fall latency (s) was measured before and after an injection of mambalgin-1 or vehicle.

\subsubsection{Grip strength test}

After training, mice were allowed to grab a metal grid and then pulled backwards so that the maximal muscular grip strength developed by the four limbs was measured just before they lost grid (Bioseb). The time-course of grip force (g) was measured before and after an injection of mambalgin-1 or vehicle. Each trial was done in duplicate.

\subsection{Pain behaviour tests}

\subsubsection{Inflammation and neuropathic pain models}

Inflammation was evoked by i.pl. injection in the left hindpaw of $20 \mu 1$ of $2 \%$ carrageenan (Sigma-Aldrich). After two hours (otherwise mentioned), the time-course of paw-flick latency or von Frey score was measured before and after injection of mambalgins, morphine or vehicle.

In other mice, an unilateral peripheral mononeuropathy was induced [3]. Briefly, mice were anaesthetized with mixed i.p. ketamine $40 \mathrm{mg} / \mathrm{kg}+$ xylazine $5 \mathrm{mg} / \mathrm{kg}$ and three chromic gut (5-0) ligatures were tied loosely (with about $1 \mathrm{~mm}$ spacing) around the common sciatic nerve. The nerve was constricted to a barely discerning degree, so that circulation through the epineurial vasculature was not interrupted. The assessment of mechanical and heat sensitivity was performed on the sciatic nerve ligated paw at day 0 (before surgery) and day 14 (after surgery). The time-course of paw flick latency or von Frey score was measured before and after injection of mambalgins, morphine or vehicle.

\subsubsection{Thermal and mechanical pain tests}

Heat pain was assessed measuring the hind paw withdrawal latency (s) from a $46^{\circ} \mathrm{C}$ bath using the paw-flick test as previously described [10], with a cutoff time at 30 seconds. 
Mechanical pain was assessed using the von Frey test. Mice were placed in individual compartments on top of a wire surface and allowed to acclimate for 1 hour before testing with a 1.4g calibrated von Frey filament (Bioseb, France). The latter was pressed perpendicularly 5 times against the mid paw and held for 3 seconds. A positive response was noted if the paw was withdrawn or licked, and the pain score was measured as the number of paw withdrawals over the 5 trials (from 0 to 5 ).

\subsection{Knockdown experiments}

A locally designed siRNA targeting ASIC1b (si-ASIC1b, CAGCAGGACAGCUCAGAAUdtdt) has been validated in vitro in COS-7 cells transfected with pCI-ratASIC1b and si-ASIC1b or a control siRNA (si-CTR; GCUCACACUACGCAGAGAUdtdt) with TransIT-LT1 and transIT-TKO (Mirus, USA), respectively. Cells were lysed $48 \mathrm{~h}$ after transfection and processed for Western blot analysis to assess the level of ASIC1b protein with the anti-ASIC1 (1:200; Neuromab) and a monoclonal antibody against actin (AC-40; 1:1,500; Sigma) as a loading control (Suppl. Fig. 1). In vivo gene silencing experiments were carried out by repeated i.t. injections of the siRNAs as previously described [10]. Briefly, siRNAs $(2 \mu \mathrm{g} /$ mouse at a ratio of $1: 4(\mathrm{w} / \mathrm{v})$ with i-Fect (Neuromics)) were injected twice a day for 3 days. After 3 days of treatment, the paw-flick latency was measured before and after induction of inflammation by carrageenan (i.pl., 2\%, 2 hours), and after i.v. injection of mambalgin-1 in carrageenan-treated animals.

\subsection{Electrophysiology in Xenopus oocytes}

ASIC currents were recorded using the two-electrode voltage-clamp (TEVC) technique in Xenopus laevis oocytes injected into the nucleus with $30 \mathrm{nl}$ of pCI-rat ASIC1a $(5 \mu \mathrm{g} / \mu \mathrm{l})$ or pCI ratASIC1b $(100 \mu \mathrm{g} / \mu \mathrm{l})$ plasmids, as previously described [19]. Briefly, oocytes were kept at $19{ }^{\circ} \mathrm{C}$ in $\mathrm{ND} 96$ solution containing $96 \mathrm{mM} \mathrm{NaCl}, 2 \mathrm{mM} \mathrm{KCl}, 1.8 \mathrm{mM} \mathrm{CaCl}_{2}, 2 \mathrm{mM} \mathrm{MgCl}_{2}$, and $5 \mathrm{mM}$ HEPES ( $\mathrm{pH} 7.4$ with $\mathrm{NaOH})$ supplemented with penicillin $(6 \mu \mathrm{g} / \mathrm{ml})$ and streptomycin (5 $\mu \mathrm{g} / \mathrm{ml}$ ). Expression of ASIC channels was tested 24 to $48 \mathrm{~h}$ after injection using a Roboocyte2 automated workstation (MultiChannelSystems MCS, Reutlingen, Germany). Oocytes were clamped at $-60 \mathrm{mV}$ and ASIC currents were activated by rapid $\mathrm{pH}$ changes from 7.4 to 5.5 in external ND96 solutions. All experiments were performed at $19-21{ }^{\circ} \mathrm{C}$ in ND96 solution supplemented with $0.05 \%$ fatty acid- and globulin-free bovine serum albumin 
(Sigma) to prevent nonspecific adsorption of the toxins to tubing and containers. Mambalgins were applied $30 \mathrm{~s}$ before the acid stimulation.

\subsection{Data analysis}

Data analysis and statistics were performed with Microcal Origin 6.0 and GraphPad Prism 4 softwares. After testing the normality of data distribution, the statistical difference between two different experimental groups was analyzed by unpaired Student's $t$-test, and between more than two different experimental groups by a one-way analysis of variance (Anova) followed by a Newman-Keuls multiple comparison test when $P<0.05$. For data within the same experimental group, a paired Student's $t$-test was used. No significant differences were observed between males and females. Cumulative effect over the first 60 minutes after injection was calculated as area under the curve (AUC, s x min) for each mouse subtracted from the control value, and expressed as mean $\pm \mathrm{SEM}$.

\section{Results}

\subsection{Intravenous injection of mambalgins evokes an anti-hyperalgesic effect in carrageenan-} induced inflammatory pain

Systemic i.v. injection in mice of synthetic Mamb-1 (0.34 nmole/mouse) two hours after an i.pl. injection of $2 \%$ carrageenan led to a decrease of the von Frey score in response to noxious mechanical stimuli (Fig. 1A) and to an increase of the paw withdrawal latency in response to noxious heat (Fig. 1B), both traducing an anti-hyperalgesic effect of the peptide. Mamb-1 transiently reversed the mechanical hyperalgesia with an efficacy that appeared to be similar to morphine $(0.31 \mu$ mole/mouse; Fig. 1A), although the test did not allow to finely discriminate between the magnitude of the maximal effects. Mamb-1 also reversed heat hyperalgesia without inducing a supplementary analgesic effect contrary to morphine (Fig. 1B), the effect being more sustained than on mechanical hyperalgesia. This anti-hyperalgesic effect reached its maximal within 30-50 minutes, the paw-flick latency increasing from $4.1 \pm$ $0.3 \mathrm{~s}$ up to $10.4 \pm 0.7 \mathrm{~s}(\mathrm{n}=23)$, a value similar to pre-injury control latency value. Synthetic Mamb-1 showed the same in vivo effect than purified Mamb-3 (Fig. 1B), as expected from their similar pharmacological profiles (Suppl. Fig. 2). The anti-hyperalgesic effect of Mamb-1 was not significantly decreased in the presence of naloxone, which blunt the effect of 
morphine as expected (Fig. 1B, right panel), and lasted up to 24 hours after the injection (Fig. 1C, left side). Interestingly, i.v. injection of Mamb-1 not only reversed inflammatory heat hyperalgesia when injected in the initial phase of inflammation (i.e., 2 hours after carrageenan), but also when injected two days after induction of the inflammation (Fig. 1C, right side). In these conditions, reversion of heat-hyperalgesia was again still present 24 hours after peptide injection. The effect on heat-hyperalgesia was concentration-dependent $\left(\mathrm{IC}_{50} \sim\right.$ $62 \mathrm{nM})$ (Fig. 1D, E), with a maximal effect at $1.7 \mu \mathrm{M}(0.34 \mathrm{nmole} /$ mouse $)$. Further increasing the dose to $8.5 \mu \mathrm{M}(1.7$ nmole/mouse) did not produce any supplementary effect (Fig. 1D).

Intravenous injection of mambalgins ( 0.34 nmole/mouse) produced no apathy, flaccid paralysis, convulsions or death. The integrated motor performances of mice on the accelerated rotarod test (Suppl. Fig. 3A) and the maximal muscular grip strength (Suppl. Fig. 3B) were not significantly affected. Mambalgins therefore showed an absence of apparent toxicity and motor effect upon systemic i.v. injection, similarly to what we found after i.t. or i.pl. injections [10].

These data demonstrate that systemic i.v. administration of mambalgins reverses both mechanical and thermal inflammatory hyperalgesia. The effect assessed using a thermal stimulus is dose-dependent and naloxone-independent, lasts up to $24 \mathrm{~h}$, and is similar after treatment whith either synthetic or purified peptides.

\subsection{The anti-hyperalgesic effect of i.v. administration of mambalgins in inflammatory pain} involves ASICla and requires peripheral ASIC1b-containing channels

We have next analyzed the mechanism of the anti-hyperalgesic effect of an $i . v$. injection of mambalgins. The effect was still present in both ASIC1a and ASIC2-knockout mice submitted to a thermal stimulus (Fig. 2A, B). However, the effect was significantly reduced in ASIC1a-knockout mice compared with wild-type animals, but not in ASIC2-knockout mice (Fig. 2C). Similar results were obtained with Mamb-3 (not shown). Since the central effect of Mamb-1 is totally suppressed in ASIC1a-knockout mice [10], these data exclude a major contribution of central ASICs in the systemic effect of the peptide.

We had previously shown the contribution of DRG-specific ASIC1b-containing channels in the i.pl. effect of mambalgins [10]. SiRNA silencing of the ASIC1b subunit in wild-type mice induced a sustained analgesia, increasing the paw-flick latency up to $15.4 \pm 1.5 \mathrm{~s}$ from $9.5 \pm 0.4 \mathrm{~s}(\mathrm{n}=11)$ (Fig. 2D, red bars) while control siRNA had no effect. These data are 
consistent with our previous data on peripheral silencing of ASIC1b in ASIC1a-knockout mice [10]. Knocking-down ASIC1b in wild-type mice also reduced the inflammatory hyperalgesia induced by i.pl. carrageenan, with an inflammatory paw flick latency of $13.9 \pm$ $1.6 \mathrm{~s}(\mathrm{n}=11)$ compared to $4.1 \pm 0.4 \mathrm{~s}(\mathrm{n}=15)$ after treatment with control siRNA (Fig. 2D, orange bars). An i.v. injection of Mamb-1 (0.34 nmole/mouse) in carrageenan-treated ASIC1b knock-down animals showed no significant analgesic effect (i.e., no increase of the paw-flick latency value), whereas similar injection in inflamed control animals (i.e., treated with control siRNA) showed a clear anti-hyperalgesic effet that was absent when vehicle only was injected (Fig. 2D, blue bars).

Altogether, these results support an important participation of peripheral ASIC1bcontaining channels and a contribution of ASIC1a-containing channels in the systemic i.v. anti-hyperalgesic effect of mambalgins.

\subsection{Mambalgins potently decrease neuropathic pain upon intravenous and central injection}

We have tested the effect of mambalgins in a mouse model of chronic constriction injury (CCI)-induced neuropathic pain. An i.v. injection of Mamb-1 (0.34 nmole/mouse) transiently reversed mechanical hyperalgesia as well as heat hyperalgesia present two weeks after surgical ligature of the sciatic nerve (Fig. 3A, B). The paw-flick latency was increased from $6.5 \pm 0.3 \mathrm{~s}$ up to $25.9 \pm 1.1 \mathrm{~s}(\mathrm{n}=10)$ by Mamb-1, and from $6.4 \pm 0.3 \mathrm{~s}$ up to $28.7 \pm 0.7 \mathrm{~s}(\mathrm{n}=$ 9) by morphine within 15-30 minutes. The effect of Mamb-1 on neuropathic-induced heat hyperalgesia was stronger but more transient that the anti-hyperalgesic effect observed on heat inflammatory pain (Fig. 1B). It was still present in mice pretreated with naloxone and in ASIC1a-knockout mice (Fig. 3B, C), suggesting an opioid- and ASICla-independent mechanism of action.

To further document the effects of Mamb-1 on neuropathic pain, we have performed central i.t. injection of the peptide ( 0.34 nmole/mouse). Interestingly, Mamb-1 also evoked a strong analgesia similar to the one induced by morphine (31 nmole/mouse; Fig. 4A, B). The paw-flick latency rapidly increased from $6.1 \pm 0.2 \mathrm{~s}$ up to $22.7 \pm 1.2 \mathrm{~s}(\mathrm{n}=12)$ after the i.t. injection of Mamb-1, and then slowly decreases but was still significant one hour after injection. When mice were pre-treated with naloxone, the analgesic effect was partly inhibited, supporting a significant contribution of the opioid system in this effect. However, a significant naloxone-insensitive analgesic effect remained (increase of the paw-flick latency from $6.7 \pm 0.4 \mathrm{~s}$ up to $15.6 \pm 0.9 \mathrm{~s}, \mathrm{n}=11,7 \mathrm{~min}$ post-i.t.). The central analgesic effect of 
Mamb-1 was completely lost in ASIC1a-knockout mice (Fig. 4A, B), which demonstrates the essential implication of ASICla-containing channels, contrary to the systemic i.v. analgesic effect on neuropathic pain that is ASIC1a-independent (Fig. 3B, C).

Altogether, these data demonstrate that mambalgins have potent analgesic effects on neuropathic pain upon central and i.v. administration but through different mechanisms that are naloxone-insensitive and ASIC1a-independent (i.v. effect), or ASIC1a-dependent and partially naloxone-sensitive (central i.t. effect).

\section{Discussion}

Three isoforms of mambalgin peptides have been isolated from the venom of black and green mamba $[1 ; 10]$. Mambalgin-1, -2 and -3 display the same pharmacological properties, inhibiting recombinant homomeric ASIC1a channels, homomeric ASIC1b channels as well as other heteromeric ASIC1a-containing and ASIC1b-containing channels, with $\mathrm{IC}_{50}$ ranging from 11 to $252 \mathrm{nM}$ [1]. The synthetic version of mambalgin-1 used in this study showed the same potency than the purified peptides. Mambalgins evoked analgesic effects after local subcutaneous injection (i.pl.) or after injection in the central nervous system (i.t.) on acute thermal pain and inflammatory-evoked thermal hyperalgesia. These effects are independent of the opioid system and involved inhibition of particular subtypes of ASIC channels, i.e., heteromeric ASIC1a/ASIC2a channels for the central analgesia, and DRG-specific ASIC1bcontaining channels for peripheral analgesia [10]. Mambalgins (i.t. or i.pl.) showed neither toxicity nor side effects. We now extend these results by showing that mambalgins also exert systemic analgesic effect after i.v. injection in inflammatory pain and in a model of neuropathic pain, in response to thermal stimuli, as previously described, but also in response to mechanical stimulation. Systemic i.v. injection of mambalgins showed no apparent toxicity or motor impairment.

The systemic $i . v$. anti-hyperalgesic effect of mambalgin-1 is dose-dependent, with a halfmaximal and maximal effect reached for estimated plasmatic concentrations of $5 \mathrm{nM}$ and 136 $\mathrm{nM}$, respectively (assuming a total blood volume of $2.5 \mathrm{ml}$ ), within the pharmacological range of ASIC channels inhibition. This effect lasts up to 24 hours on inflammatory heat hyperalgesia. Mamb-1 is also active when injected two days after induction of the inflammation by carrageenan, which broadens the temporal therapeutic window of the peptide in inflammatory pain. The anti-hyperalgesic effect of mambalgins is still present in ASIC2 
and ASICla-knockout mice, but however significantly lower in these latter animals, which demonstrates that it partially depends on ASIC1a but not ASIC2 proteins. It is currently not known if mambalgins can penetrate the blood-brain barrier but a major participation in the effect of ASICla-containing channels expressed in the central nervous system is unlikely, because i) the analgesic effect associated with central injection of mambalgins was blunted in ASICla-knockout mice [10] while the systemic $i . v$. effect was only partially impacted and ii) silencing DRG-specific ASIC1b in wild-type mice significantly inhibited the systemic i.v. analgesia associated with Mamb-1. We thus propose that i.v. injection of mambalgins induces an anti-hyperalgesic effect mainly through inhibition of peripheral ASIC1b-containing channels, similarly to the analgesic effect previously described after local intraplantar injection of the peptides [10]. However, and contrary to local i.pl. injection, the systemic i.v. effect involves an additional smaller contribution of ASIC1a-containing channels, possibly via central ASICla-containing channels. Indeed, local i.pl. injection of Mamb-1 does not seem to induce a systemic effect because a significant analgesia in the inflamed hindpaw was only observed after ipsilateral but not contralateral i.pl. injection of the peptide (Suppl. Fig 4). This is in good agreement with the fact that the analgesic effect of i.pl. injection of Mamb-1 is not affected in ASIC1a knockout mice and does not therefore involve ASICla-containing channels [10].

Mambalgins have been tested on acute and inflammatory pain, but not on more chronic conditions such as those associated with nerve injury. In addition, these peptides are able to inhibit different subtypes of ASIC channels in both central neurons and nociceptors, making them interesting tools in the study of mechanisms associated with ASIC channel in neuropathic pain, which remains poorly understood. We report here that mambalgins have a potent analgesic effect in an experimental model (CCI) of neuropathic pain upon both systemic (i.v.) and central (i.t.) injection. The mechanisms underlying these effects appear to be different. Intravenous injection of Mamb-1 exerts an analgesic effect that is insensitive to naloxone and is still present in ASIC1a-knockout mice, whereas the analgesic effect of i.t. injection is partly inhibited by naloxone and is absent in ASIC1a-knockout mice. ASIC1acontaining channels appear thus essential for the central (i.t.) but not the peripheral (i.v.) effect of mambalgins in neuropathic pain, similarly to what we observed in inflammatory hyperalgesia (this work and [10]). However, the central i.t. effect of Mamb-1 in neuropathic pain is significantly different from the effect we have previously described in acute and inflammatory pain [10] because it is significantly decreased by naloxone. This suggests differences in the central ASICla-containing channels primarily targeted by the peptide in 
inflammatory and neuropathic pain conditions. We have shown previously that different pathways in the central nervous system involving different subtypes of ASIC channels can lead to opioid-sensitive (ASIC1a and/or ASIC1a/ASIC2b channels) or opioid-insensitive (ASIC1a/ASIC2a channels) analgesia [10] [17]. Heteromeric ASIC1a/ASIC2a channels might be therefore the major contributors to the effect in inflammatory pain because it is mainly naloxone-insensitive. These channels may also participate in the effect of mambalgins in neuropathic pain, which has a significant naloxone-insensitive component, whereas homomeric ASIC1a and/or heteromeric ASIC1a/ASIC2b channels could be involved in the naloxone-sensitive part. Interestingly, intrathecal injection in mice of the spider toxin PcTx1 (an inhibitor of ASIC1a and ASIC1a/ASIC2b channels) evoked a naloxone-sensitive analgesic effect in neuropathic pain that was only half the effect of morphine [17]. This effect is indeed similar to the naloxone-sensitive component of the i.t. mambalgin-1 analgesia described here in the CCI model, consistent with the fact that the peptide also inhibits ASIC1a and ASIC1a/ASIC2b channels similarly to PcTx1. The greater analgesic effect associated with mambalgin-1, which is comparable to that of morphine, is supported by the additional inhibition of ASIC1a/ASIC2a channels. The effect of mambalgin-1 therefore unveils a differential participation of ASICla-containing channels expressed in the central nervous system in different pain conditions; i.e., acute and inflammatory pain versus neuropathic pain, which may reflect pathophysiological changes in the expression of ASIC channel subtypes in particular neurons of the spinal cord and/or the brain. A similar situation could also occur in sensory neurons because the peripheral effect of $i . v$. mambalgin-1 in neuropathic pain is more potent than the one in inflammatory pain and is totally ASIC1a-independent, suggesting differences in the relative participation and/or the subtypes of peripheral ASIC channels targeted by the peptide in neuropathic pain (corresponding most probably to ASIC1bcontaining channels).

Our data show a potent systemic analgesic effect of mambalgins upon intravenous administration on both inflammatory and neuropathic pain, which opens new potential therapeutic perspectives for these peptides besides their previously described effects. Our findings also support the pathophysiological involvement of peripheral ASIC1b-containing channels in inflammatory and probably neuropathic pain, as well as the important role of central ASIC1a-containing channels in neuropathic pain.

\section{Acknowledgments}


We thank E. Deval, J. Noël, M. Salinas, M. Chafai, S. Marra and T. Besson for helpful discussions, M. Lazdunski for his support, C. Chevance for secretarial assistance and V. Thieffin for mice breeding. This work was supported by the Fondation pour la Recherche Medicale (DEQ20110421309) and the Agence Nationale de la Recherche (ANR-13-BSV40009).

\section{Conflict of interest statement}

The authors declare no conflict of interest. 
References

[1] Baron A, Diochot S, Salinas M, Deval E, Noel J, Lingueglia E. Venom toxins in the exploration of molecular, physiological and pathophysiological functions of acidsensing ion channels. Toxicon 2013;75:187-204.

[2] Baron A, Lingueglia E. Pharmacology of acid-sensing ion channels - Physiological and therapeutical perspectives. Neuropharmacology 2015; doi: 10.1016/j.neuropharm.2015.01.005.

[3] Bennett GJ, Xie YK. A peripheral mononeuropathy in rat that produces disorders of pain sensation like those seen in man. Pain 1988;33(1):87-107.

[4] Bohlen CJ, Chesler AT, Sharif-Naeini R, Medzihradszky KF, Zhou S, King D, Sanchez EE, Burlingame AL, Basbaum AI, Julius D. A heteromeric Texas coral snake toxin targets acid-sensing ion channels to produce pain. Nature 2011;479(7373):410-414.

[5] Deval E, Gasull X, Noel J, Salinas M, Baron A, Diochot S, Lingueglia E. Acid-sensing ion channels (ASICs): pharmacology and implication in pain. Pharmacol Ther 2010;128(3):549-558.

[6] Deval E, Lingueglia E. Acid-Sensing Ion Channels and nociception in the peripheral and central nervous systems. Neuropharmacology 2015; doi: 10.1016/j.neuropharm.2015.02.009.

[7] Deval E, Noel J, Gasull X, Delaunay A, Alloui A, Friend V, Eschalier A, Lazdunski M, Lingueglia E. Acid-sensing ion channels in postoperative pain. J Neurosci 2011;31(16):6059-6066.

[8] Deval E, Noel J, Lay N, Alloui A, Diochot S, Friend V, Jodar M, Lazdunski M, Lingueglia E. ASIC3, a sensor of acidic and primary inflammatory pain. EMBO J 2008;27(22):3047-3055.

[9] Diochot S, Baron A, Rash LD, Deval E, Escoubas P, Scarzello S, Salinas M, Lazdunski M. A new sea anemone peptide, APETx2, inhibits ASIC3, a major acid-sensitive channel in sensory neurons. Embo J 2004;23(7):1516-1525.

[10] Diochot S, Baron A, Salinas M, Douguet D, Scarzello S, Dabert-Gay AS, Debayle D, Friend V, Alloui A, Lazdunski M, Lingueglia E. Black mamba venom peptides target acid-sensing ion channels to abolish pain. Nature 2012;490(7421):552-555.

[11] Escoubas P, De Weille JR, Lecoq A, Diochot S, Waldmann R, Champigny G, Moinier D, Menez A, Lazdunski M. Isolation of a tarantula toxin specific for a class of proton-gated $\mathrm{Na}^{+}$channels. J Biol Chem 2000;275(33):25116-25121.

[12] Ettaiche M, Guy N, Hofman P, Lazdunski M, Waldmann R. Acid-sensing ion channel 2 is important for retinal function and protects against light-induced retinal degeneration. J Neurosci 2004;24(5):1005-1012.

[13] Grunder S, Pusch M. Biophysical properties of acid-sensing ion channels (ASICs). Neuropharmacology 2015; doi: 10.1016/j.neuropharm.2014.12.016.

[14] Izumi M, Ikeuchi M, Ji Q, Tani T. Local ASIC3 modulates pain and disease progression in a rat model of osteoarthritis. J Biomed Sci 2012;19:77.

[15] Karczewski J, Spencer RH, Garsky VM, Liang A, Leitl MD, Cato MJ, Cook SP, Kane S, Urban MO. Reversal of acid-induced and inflammatory pain by the selective ASIC3 inhibitor, APETx2. Br J Pharmacol 2010;161(4):950-960.

[16] Lin SH, Sun WH, Chen CC. Genetic exploration of the role of acid-sensing ion channels. Neuropharmacology 2015; doi: 10.1016/j.neuropharm.2014.12.011.

[17] Mazzuca M, Heurteaux C, Alloui A, Diochot S, Baron A, Voilley N, Blondeau N, Escoubas P, Gelot A, Cupo A, Zimmer A, Zimmer AM, Eschalier A, Lazdunski 
M. A tarantula peptide against pain via ASIC1a channels and opioid mechanisms. Nat Neurosci 2007;10(8):943-945.

[18] Rustay NR, Wahlsten D, Crabbe JC. Influence of task parameters on rotarod performance and sensitivity to ethanol in mice. Behav Brain Res 2003;141(2):237-249.

[19] Salinas M, Besson T, Delettre Q, Diochot S, Boulakirba S, Douguet D, Lingueglia E. Binding site and inhibitory mechanism of the mambalgin-2 pain-relieving peptide on acid-sensing ion channel 1a. J Biol Chem 2014;289(19):13363-13373.

[20] Sherwood TW, Lee KG, Gormley MG, Askwith CC. Heteromeric Acid-Sensing Ion Channels (ASICs) Composed of ASIC2b and ASIC1a Display Novel Channel Properties and Contribute to Acidosis-Induced Neuronal Death. J Neurosci 2011;31(26):9723-9734.

[21] Sluka KA, Price MP, Breese NM, Stucky CL, Wemmie JA, Welsh MJ. Chronic hyperalgesia induced by repeated acid injections in muscle is abolished by the loss of ASIC3, but not ASIC1. Pain 2003;106(3):229-239.

[22] Staniland AA, McMahon SB. Mice lacking acid-sensing ion channels (ASIC) 1 or 2, but not ASIC3, show increased pain behaviour in the formalin test. Eur J Pain 2009;13(6):554-563.

[23] Waldmann R, Champigny G, Bassilana F, Heurteaux C, Lazdunski M. A protongated cation channel involved in acid-sensing. Nature 1997;386(6621):173-177.

[24] Wemmie JA, Chen J, Askwith CC, Hruska-Hageman AM, Price MP, Nolan BC, Yoder PG, Lamani E, Hoshi T, Freeman JH, Jr., Welsh MJ. The acid-activated ion channel ASIC contributes to synaptic plasticity, learning, and memory. Neuron 2002;34(3):463-477.

[25] Wemmie JA, Taugher RJ, Kreple CJ. Acid-sensing ion channels in pain and disease. Nat Rev Neurosci 2013;14(7):461-471. 


\section{Figure legends}

Fig. 1: Intravenous injection of mambalgin-1 evokes anti-hyperalgesic effects in inflammatory pain.

A, Effect of i.v. Mamb-1 (0.34 nmole/mouse) and morphine (0.31 $\mu$ mole/mouse) on inflammatory mechanical hyperalgesia (carrageenan $2 \%, 2 \mathrm{~h}$ ) determined using the von Frey test. The von Frey score corresponds to the number of paw lifts out of five mechanical stimulations with a $1.4 \mathrm{~g}$ filament. Mean $\pm \mathrm{SEM}, \mathrm{n}=10 .^{*}, \mathrm{p}<0.05 ;{ }^{*}, \mathrm{p}<0.001 ; * * *, \mathrm{p}<0.005$, Anova + NK post-test versus vehicle. B, Effect of i.v. Mamb-1, Mamb-3 (0.34 nmole/mouse) and morphine $(0.31 \mu$ mole/mouse) on inflammatory heat hyperalgesia (carrageenan $2 \%, 2 \mathrm{~h}$ ) determined using the paw-immersion test $\left(46^{\circ} \mathrm{C}\right)$. Right panel, area under curve (AUC, s x min) calculated over 1 hour from each mouse. Mean $\pm \mathrm{SEM}, \mathrm{n}=8-23 .{ }^{*}, \mathrm{p}<0.05 ;{ }^{* *}, \mathrm{p}<0.001$; ***, $\mathrm{p}<0.005$, ns, $\mathrm{p}>0.05$ not significant, Anova $+\mathrm{NK}$ post-test compared to vehicle, unless otherwise mentioned. Some time-course curves are not shown for clarity. C, Paw-flick latency (s) recorded before $(0 \mathrm{~min})$ and at various times after i.v. injection of Mamb-1. Injection of Mamb-1 two hours (left side, $n=14$ ) or two days (right side, $n=9$ ) after carrageenan (CAR). Mean \pm SEM. ${ }^{*}, \mathrm{p}<0.05 ; * *, \mathrm{p}<0.001 ; * * *, \mathrm{p}<0.005$, ns, $\mathrm{p}>0.05$ not significant, paired $t$-test compared to control latency, black symbols, or compared to hyperalgesic latency (CAR), red symbols. D, Dose-dependent effect of i.v. Mamb-1 on inflammatory heat hyperalgesia (carrageenan $2 \%, 2 \mathrm{~h}$ ) determined using the paw-immersion test $\left(46^{\circ} \mathrm{C}\right)$. Area under curve (AUC, s x min) calculated over 1 hour from each mouse. Mean \pm SEM, $n=8-23$. ${ }^{* *}, \mathrm{p}<0.001$; ***, $\mathrm{p}<0.005$, Anova + NK post-test compared to vehicle. Right panel: dose-response curve. Data were fitted by a sigmoidal curve with an $\mathrm{EC}_{50}$ of $62 \mathrm{nM}$, a Hill slop number of 0.7 , and a maximal effect at $1.7 \mu \mathrm{M}$.

Fig. 2: ASIC1-containing channels are involved in the systemic $i . v$. analgesic effect of mambalgin-1 in inflammatory pain.

A, B, Effect of i.v. Mamb-1 (0.34 nmole/mouse) on inflammatory heat hyperalgesia (carrageenan $2 \%, 2 \mathrm{~h}$ ) determined using the paw-immersion test $\left(46^{\circ} \mathrm{C}\right)$ in $\mathrm{ASICla}$-knockout (A; ASIC1a-KO) and ASIC2-knockout (B; ASIC2-KO) mice. Mean \pm SEM, n=11-16. **, $\mathrm{p}<0.001 ;{ }^{* *}, \mathrm{p}<0.005$, Anova $+\mathrm{NK}$ post-test compared to vehicle. $\mathbf{C}$, Analgesic effect over 1 hour (AUC) evaluated using the paw-flick test on wild-type (WT), ASIC1a-KO and ASIC2KO mice. Mean \pm SEM, $\mathrm{n}=8-23$. **, $\mathrm{p}<0.001$; ***, $\mathrm{p}<0.005$, ns, $\mathrm{p}>0.05$ not significant, Anova + NK post-test compared to corresponding vehicle (black symbols) or compared to 
WT mice (blue symbols) unless otherwise mentioned. D, Paw-flick latency before (control) and after treatment with si-CTR or siRNA against ASIC1b (si-ASIC1b) in wild-type mice upon normal and inflammatory conditions (carrageenan, CAR, 2\%, 2h). Intravenous injection of Mamb-1 (0.34 nmole/mouse) or vehicle was performed in siRNA-treated mice two hours after carrageenan injection (protocol shown above the graph) and the paw-flick latency was evaluated 52 minutes after peptide injection. Mean \pm SEM, $\mathrm{n}=8-15$. $^{*}, \mathrm{p}<0.05 ;{ }^{* *}, \mathrm{p}<0.001$; ***, $\mathrm{p}<0.005$, ns, $\mathrm{p}>0.05$ not significant, paired $t$-test compared with untreated control (i.e., before siRNA injections).

Fig. 3: Intravenous injection of mambalgin-1 evokes analgesic effects in neuropathic pain.

A, Effect of i.v. Mamb-1 (0.34 nmole/mouse) and morphine (0.31 $\mu$ mole/mouse $)$ on mechanical hyperalgesia in the CCI model of neuropathic pain 14 days after surgery, determined using the von Frey test. The von Frey score corresponds to the number of paw lifts out of five mechanical stimulations with a $1.4 \mathrm{~g}$ filament. Mean \pm SEM, n=7-10. B, Effect of i.v. Mamb-1 (0.34 nmole/mouse) and morphine (0.31 $\mu$ mole/mouse) on thermal hyperalgesia in the CCI model of neuropathic pain determined using the paw-immersion test $\left(46^{\circ} \mathrm{C}\right)$ in wild-type (WT) and ASIC1a-knockout mice (ASIC1a-KO). Mean \pm SEM, $n=8-10$. Note that ASICla-KO mice have no difference in paw withdrawal latency compared with WT animals, which is consistent with the absence of major basal pain phenotype that has been already described in these animals $[21 ; 22]$. C, Analgesic effect over 1 hour (AUC) evaluated using the paw-flick test after an i.v. injection of Mamb-1, morphine or vehicle, in neuropathic wildtype (WT) and ASIC1a-KO mice, with or without pre-treatment with subcutaneous naloxone

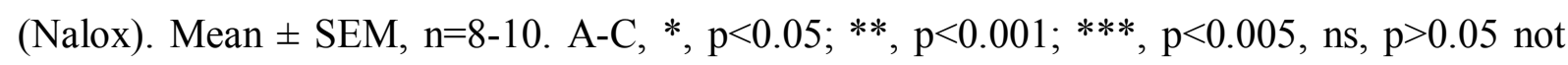
significant, Anova $+\mathrm{NK}$ post-test compared to vehicle, unless otherwise specified. \#\#, $\mathrm{p}<0.001$; \#\#\#, $\mathrm{p}<0.005$, Anova $+\mathrm{NK}$ post-test compared to vehicle in ASIC1a-knockout mice. For clarity, some time-course curves are not shown in B.

\section{Fig. 4: Intrathecal injection of mambalgin-1 exerts ASIC1a-dependent analgesia in neuropathic pain.}

A, Effect of i.t. Mamb-1 (0.34 nmole/mouse) and morphine (31 nmole/mouse) on thermal hyperalgesia in the CCI model of neuropathic pain determined using the paw-immersion test $\left(46^{\circ} \mathrm{C}\right.$ ) in wild-type (WT) and ASIC1a-knockout mice (ASIC1a-KO). Mean $\pm \mathrm{SEM}, \mathrm{n}=8-12$. *, $\mathrm{p}<0.05 ; * *, \mathrm{p}<0.001 ; * * *, \mathrm{p}<0.005$, Anova + NK post-test versus vehicle; \#\#, $\mathrm{p}<0.001$; 
\#\#\#, $\mathrm{p}<0.005$, Anova + NK post-test versus Mamb-1 in mice not pre-treated by naloxone (Nalox). B, Analgesic effect over 1 hour (AUC) evaluated using the paw-flick test after an i.t. injection of Mamb-1, morphine or vehicle, in neuropathic wild-type (WT) and ASIC1a-KO mice, with or without pre-treatment with subcutaneous naloxone (Nalox). Mean $\pm \mathrm{SEM}, \mathrm{n}=8$ 12. ${ }^{*}, \mathrm{p}<0.05 ; * * *, \mathrm{p}<0.005$, ns, $\mathrm{p}>0.05$ not significant, Anova + NK post-test compared to vehicle, unless otherwise mentioned.

\section{Suppl Fig. 1: In vitro validation of the siRNA targeting ASIC1b.}

A-C, siRNA targeting ASIC1b (si-ASIC1b) and control siRNA (si-CTR) were co-transfected in COS-7 cells with a plasmid coding for rat ASIC1b (pCI-ratASIC1b). The level of protein was assessed 48h after transfection by Western blot (in B) with an ASIC1-specific antibody. The blot was also probed with a monoclonal antibody against actin to normalize for protein loading. A densitometric quantification of the signal has been done in $\mathbf{C}$ and showed a $80 \%$ reduction of ASIC1b expression by si-ASIC1b treatment compared to si-CTR. A.U, arbitrary units. Mean \pm S.E.M. $* * *: p<0.001$ compared with si-CTR, unpaired $t$-test.

Suppl. Fig 2: Inhibition by synthetic mambalgin-1 of recombinant rat ASIC1a and rat ASIC1b channels expressed in Xenopus oocytes.

Dose-reponse curves of inhibition (\% of control current) of homomeric ratASIC1a current (A) and homomeric rat ASIC1b current (B) heterologously expressed in Xenopus oocytes by synthetic mambalgin-1 (sMamb-1) compared to native purified mambalgin-3 (Mamb-3). Mean \pm SEM, $n=3-7$ Curves were fitted according the sigmoidal dose-response equation: $\mathrm{Y}=$ current $\% /\left(1+10^{\wedge}\left(\left(\log I C_{50}-X\right) * n_{H}\right)\right)$, with $n_{H}$ the Hill slope number and $\mathrm{IC}_{50}$ the concentration that inhibits $50 \%$ of the control current.

\section{Suppl. Fig 3: Systemic i.v. injection of mambalgin-1 showed no motor impairment.}

A, Accelerated rotarod test. Time-course of fall latency (s) after an i.v. injection of Mamb-1 (0.34 nmole/mouse) or vehicle, expressed as a ratio of the control latency before injection. Mean \pm SEM, $\mathrm{n}=11-12$. $\mathrm{p}>0.005$, unpaired $t$-test. The control fall latency was $133 \pm 7 \mathrm{~g}$ $(\mathrm{n}=11)$. B, Grip Test. Time-course of maximal grip strength ( $\mathrm{g}$ ) of all four limbs after an i.v. injection of Mamb-1 (0.34 nmole/mouse) or vehicle, expressed as a ratio of the control strength before injection. Mean \pm SEM, $\mathrm{n}=13-17$. $\mathrm{p}>0.05$, unpaired $t$-test. Control maximal grip strength was $130 \pm 6 \mathrm{~g}(\mathrm{n}=13)$. 
Suppl Fig. 4: Local analgesic effect of mambalgin-1 on thermal inflammatory hyperalgesia after intraplantar (i.pl.) injection.

Effect of i.pl. injection of mambalgin-1 ( $0.34 \mathrm{nmole} /$ mouse $)$ in the left or the right hindpaw (vehicle: saline $+0.05 \%$ BSA) on carrageenan-induced heat hyperalgesia when injected two hours after i.pl. carrageenan $(2 \%, 20 \mu l)$ in the left hindpaw. Mean \pm SEM, n=15-22. *, $\mathrm{p}<0.05 ; * *, \mathrm{p}<0.001 ; * * *, \mathrm{p}<0.005, \mathrm{~ns}, \mathrm{p}>0.05$ not significant, Anova $+\mathrm{NK}$ post-test compared to vehicle. \#, $\mathrm{p}<0.05$; \#\#, $\mathrm{p}<0.001$; \#\#\#, $\mathrm{p}<0.005$, Anova + NK post-test compared to i.pl. injection into the right hindpaw. 


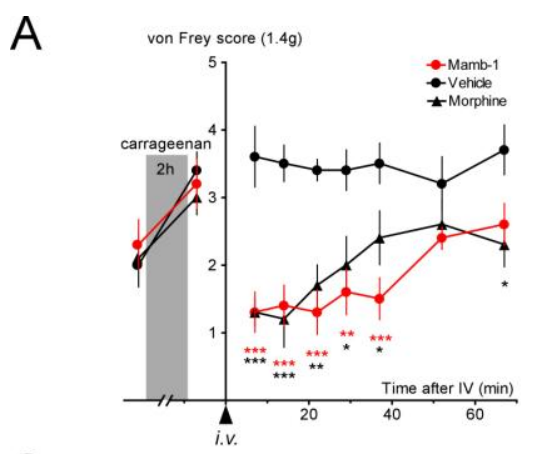

C

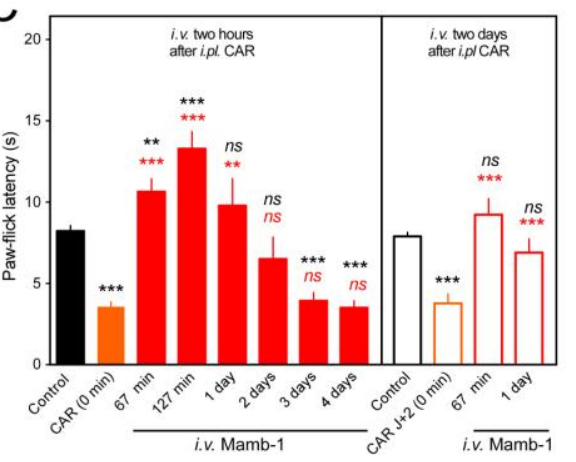

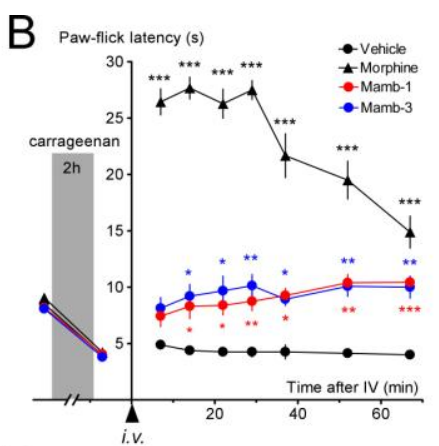

D

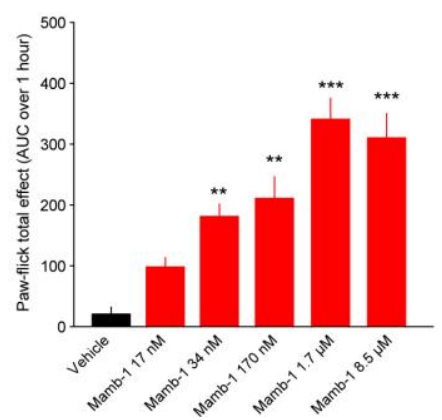

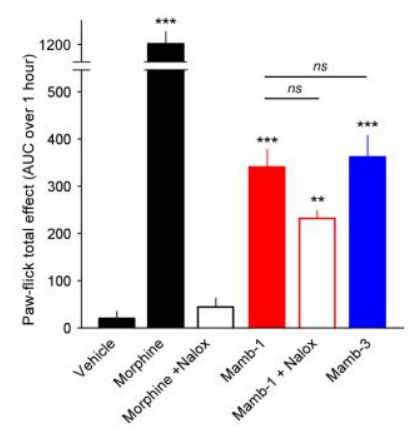

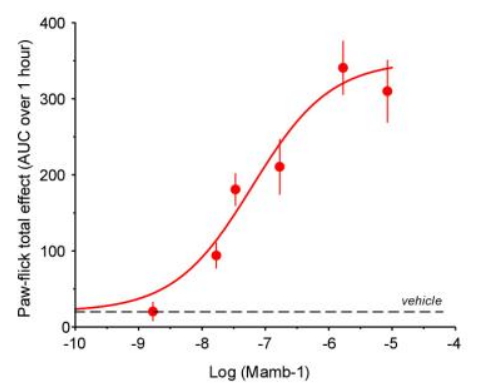



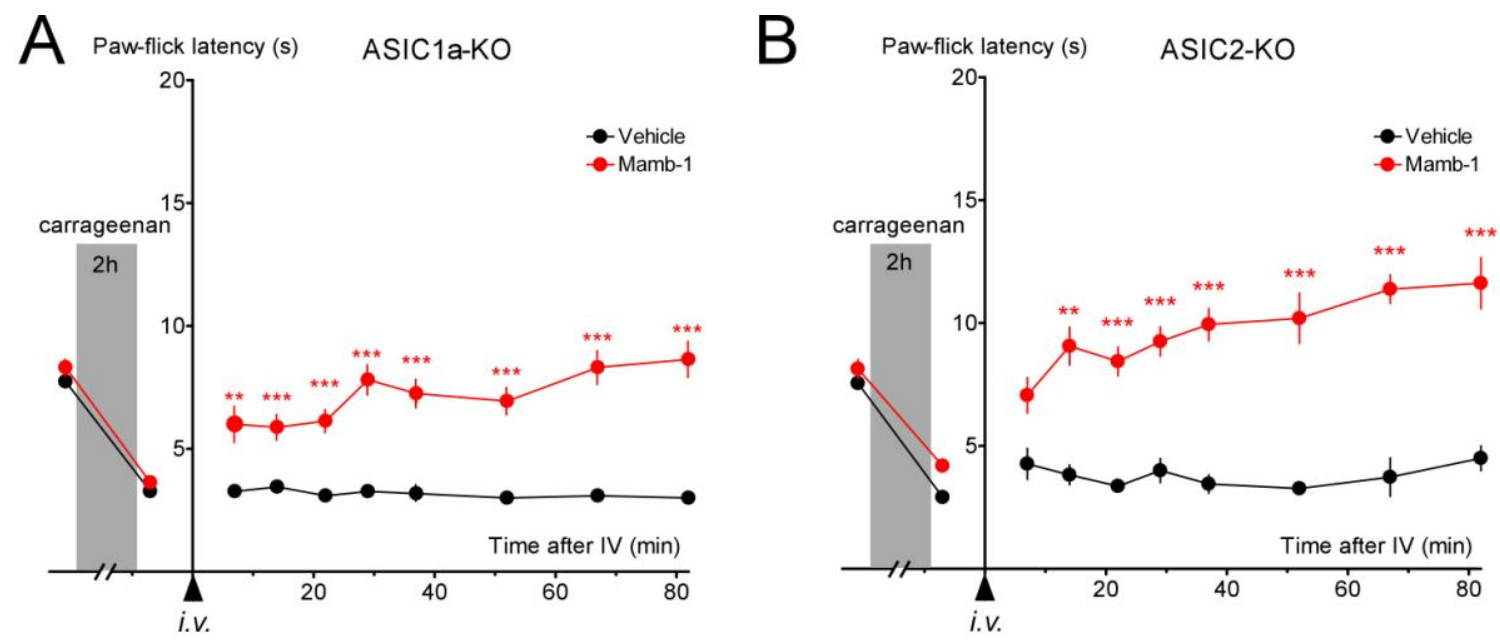

C
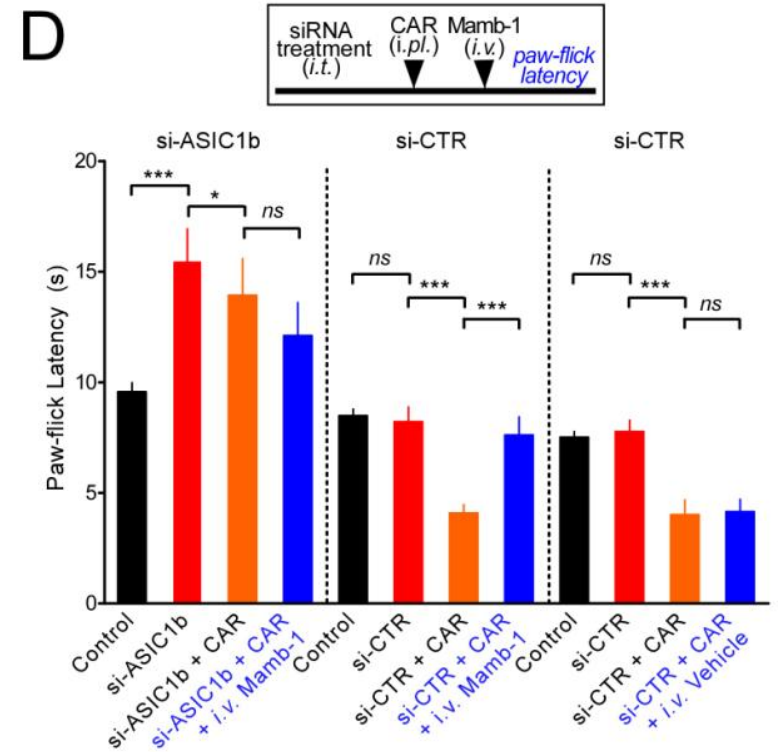
A

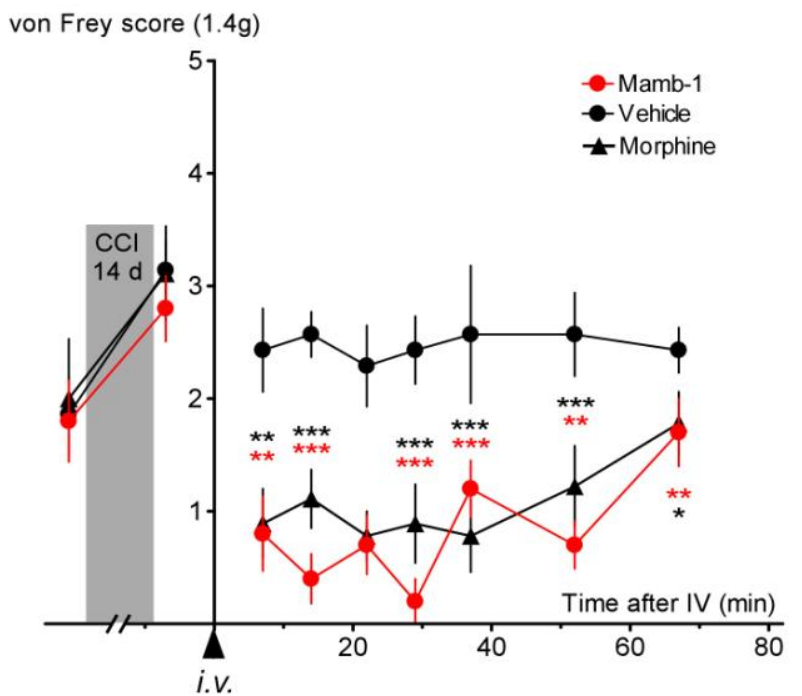

B

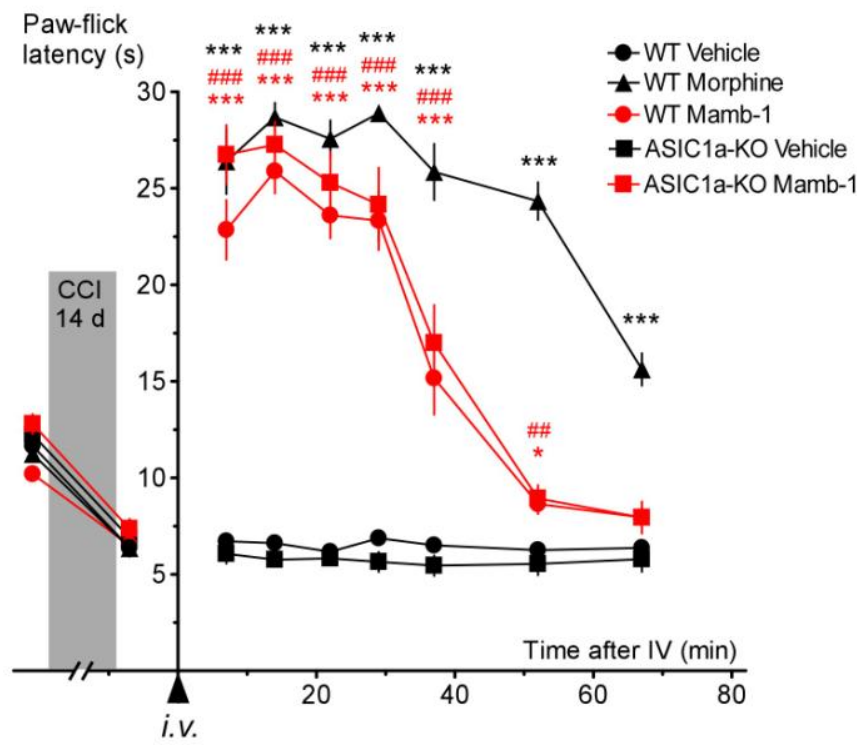

C

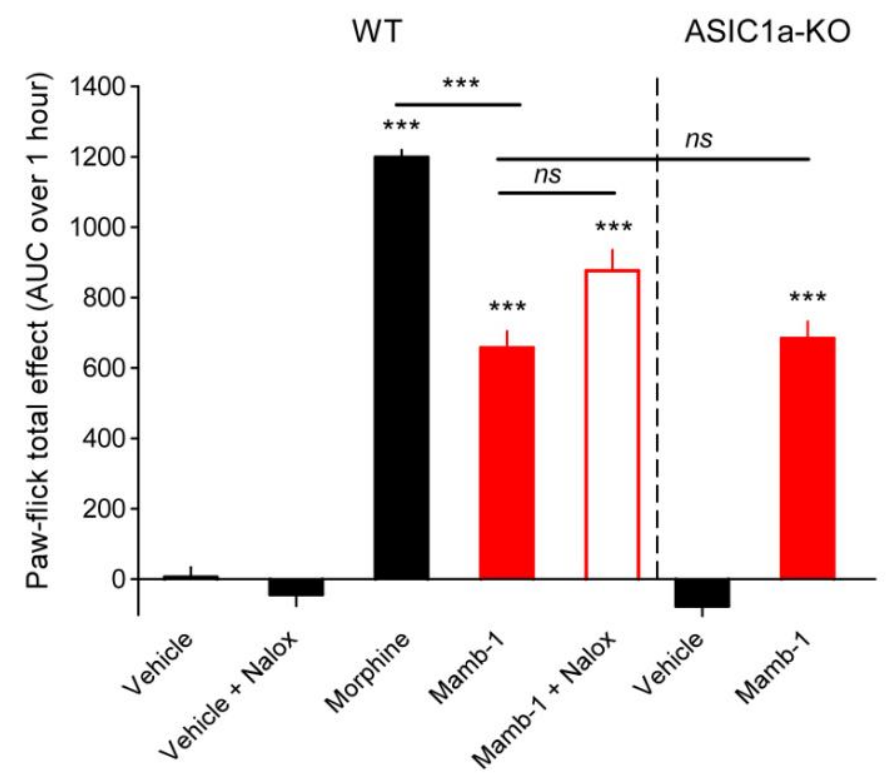


A

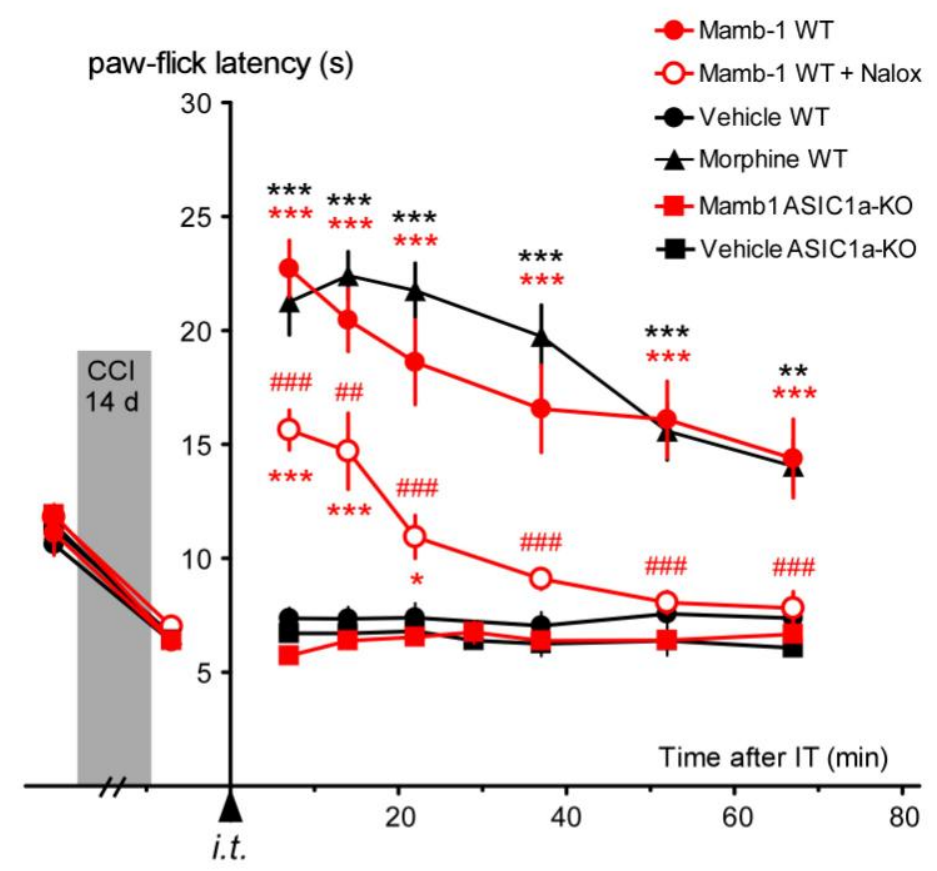

B

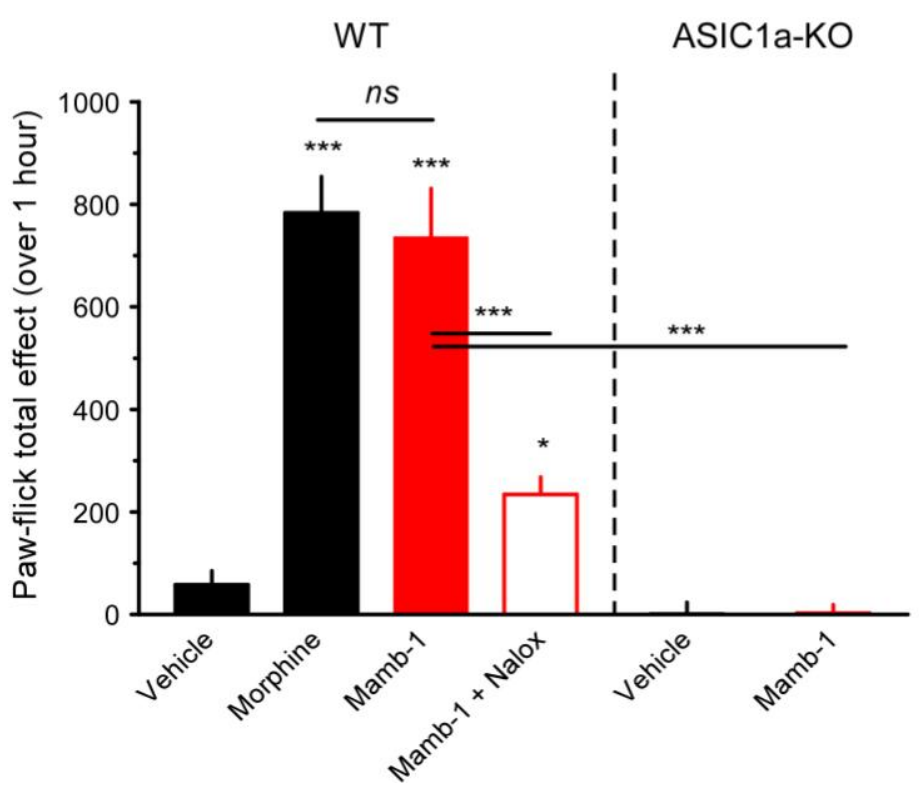


A

ASIC1a

ASIC1b

si-ASIC1b

B

ASIC1b

actin

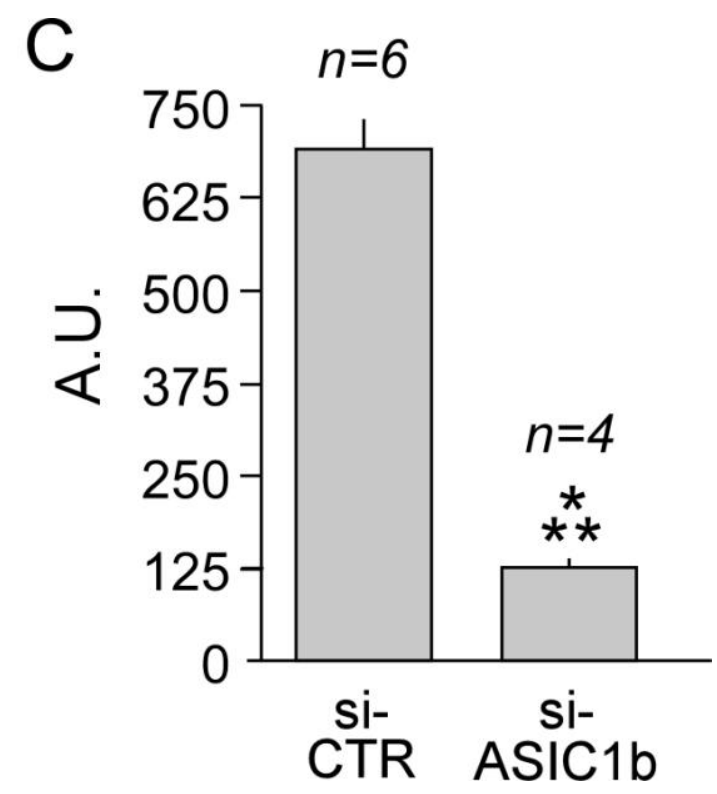


A

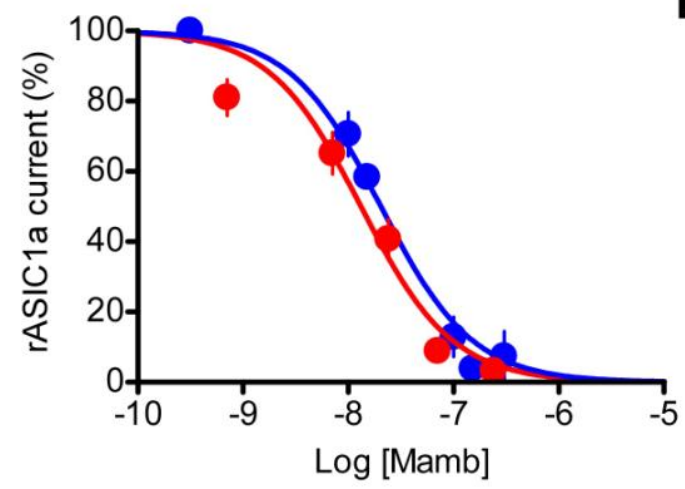

- sMamb-1 $I_{50}=13 \mathrm{nM}, \mathrm{n}_{\mathrm{H}}=-1$

- Mamb-3 $I C_{50}=20 \mathrm{nM}, \mathrm{n}_{\mathrm{H}}=-1$
B

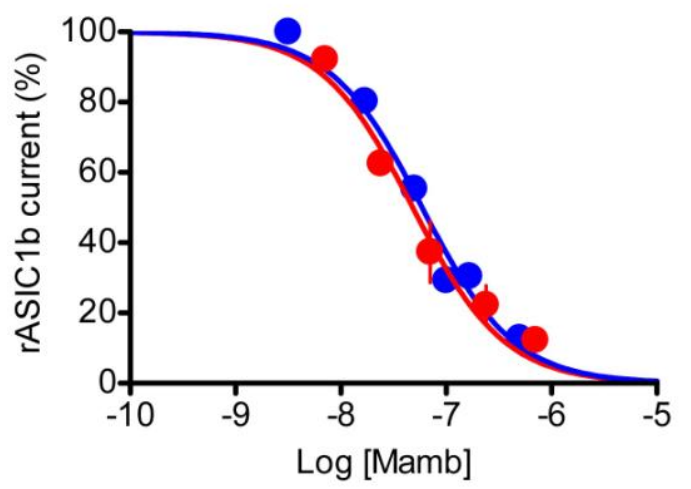

- sMamb-1 $I_{50}=48 \mathrm{nM}, \mathrm{n}_{\mathrm{H}}=-1$

- Mamb-3 $\mathrm{IC}_{50}=59 \mathrm{nM}, \mathrm{n}_{\mathrm{H}}=-1$ 

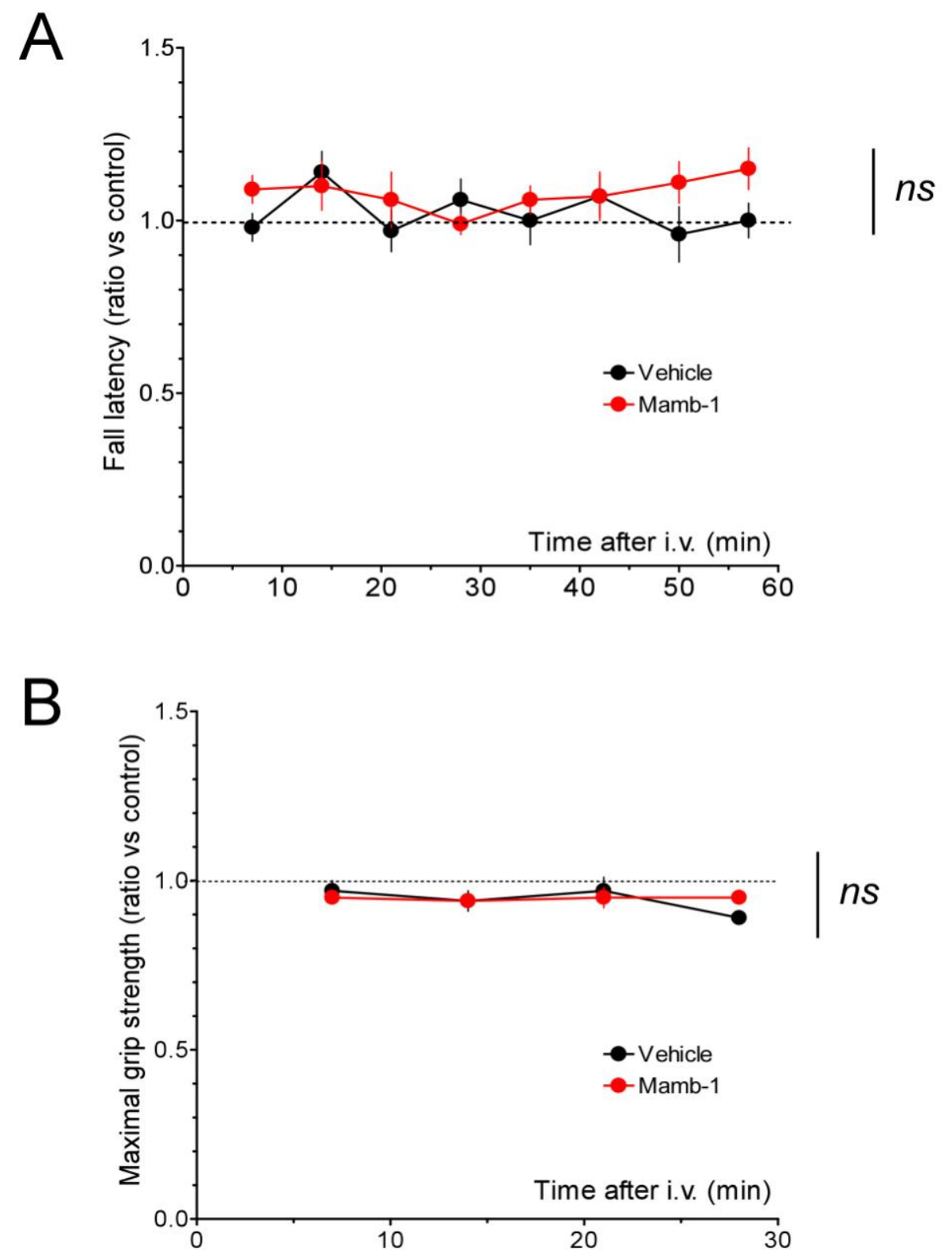


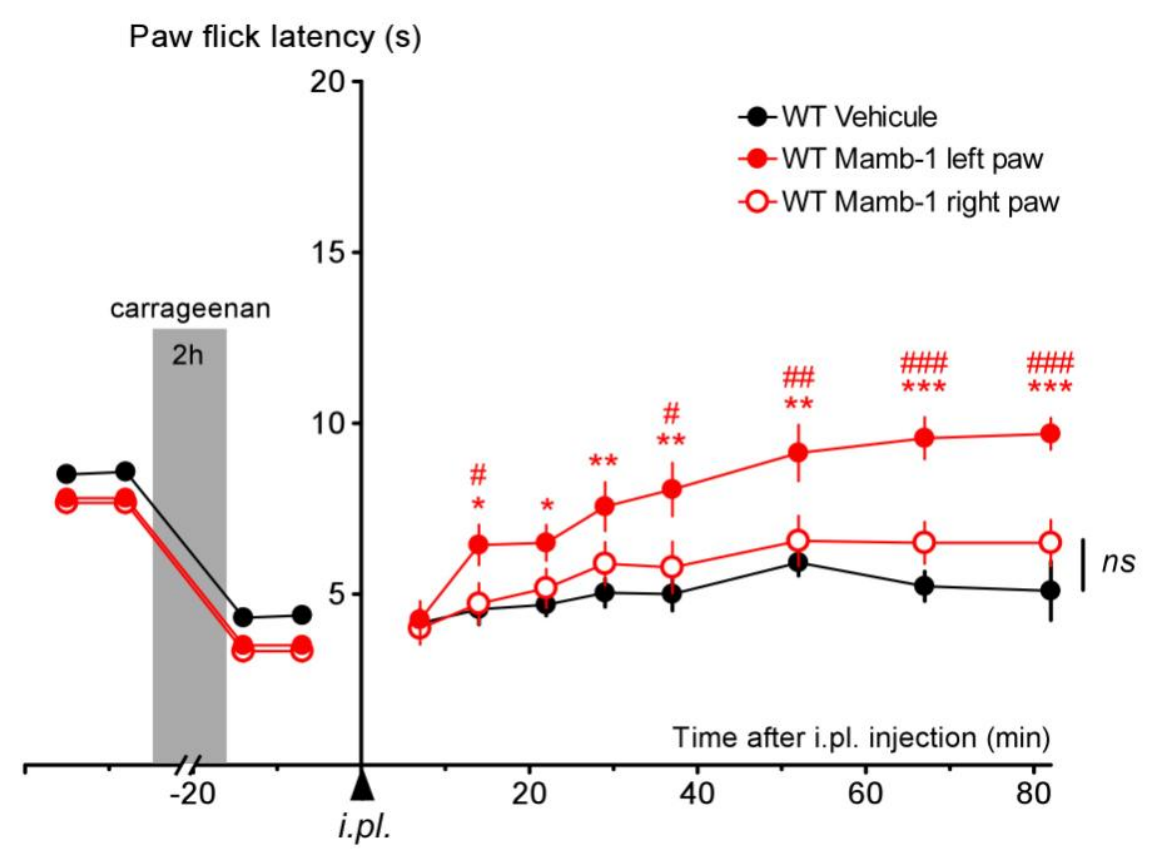

